\title{
Immobilized dye-decolorizing peroxidase (DyP) and directed evolution variants for hydrogen peroxide biosensing
}

\author{
Catarina Barbosa $^{1 \dagger}$, Célia M. Silveira ${ }^{1 \dagger}$, Diogo Silva ${ }^{1}$, Vânia Brissos ${ }^{1}$, Peter Hildebrandt ${ }^{2}$, Lígia $^{\circ}$ \\ O. Martins ${ }^{1^{*}}$ and Smilja Todorovic ${ }^{1^{*}}$ \\ ${ }^{1}$ Instituto de Tecnologia Química e Biológica António Xavier, Universidade NOVA de Lisboa, \\ Av. da República, 2780-157 Oeiras, Portugal \\ ${ }^{2}$ Technische Universität Berlin, Inbstitut für Chemie, Sekr. PC14, Straße des 17. Juni 135, D- \\ 10623 Berlin, Germany \\ "The authors contributed equally to the work.
*Corresponding authors. Email:smilja@itqb.unl.pt
}

\begin{abstract}
Immobilized dye-decolorizing peroxidase from Pseudomonas putida MET94 (PpDyP) and three variants generated by directed evolution (DE) are studied aiming at the design of a biosensor for $\mathrm{H}_{2} \mathrm{O}_{2}$ detection. Structural properties of the enzymes in solution and immobilized state are addressed by resonance Raman (RR) and surface enhanced RR (SERR) spectroscopy, and the electrocatalytic properties are analyzed by electrochemistry. The wild-type (wt) and 29E4 variant (with E188K and H125Y mutations) represent excellent candidates for development of $\mathrm{H}_{2} \mathrm{O}_{2}$ biosensors, since they exhibit a good dynamic response range $\left(1-200 \mu \mathrm{M} \mathrm{H}_{2} \mathrm{O}_{2}\right)$, short response times $(2 \mathrm{~s})$ and a superior sensitivity $\left(1.3-1.4 \mathrm{~A} \cdot \mathrm{M}^{-1} \cdot \mathrm{cm}^{-2}\right)$ for $\mathrm{H}_{2} \mathrm{O}_{2}$, as well as selectivity and long term stability. In contrast to the solution state, 6E10 (with E188K, A142V and H125Y mutations) and 25F6 (with E188K, A142V, H125Y and G129D mutations) variants display much lower activity and are inhibited by high concentrations of $\mathrm{H}_{2} \mathrm{O}_{2}$ upon adsorption on an electrode. In terms of sensitivity, the tested bioelectrodes employing wt PpDyP and 29E4 variant outperform HRP based counterparts reported in the literature by 1 to 4 orders of magnitude. We propose the development of wt or 29E4 PpDyP based biosensor as a valuable alternative to devices that rely on other peroxidases.
\end{abstract}

Keywords: biosensor, hydrogen peroxide, dye decolorizing peroxidase, directed evolution, direct electron transfer, surface enhanced resonance Raman spectroscopy 


\section{Introduction}

Mediatorless $3^{\text {rd }}$ generation biosensors rely upon direct electron transfer (DET) between an immobilized enzyme and an electrode, allowing for a sensitive detection of the enzyme's substrate (Bollella and Gorton 2018; Das et al. 2016). In this respect, peroxidases represent an obvious choice for the design of $\mathrm{H}_{2} \mathrm{O}_{2}$ biosensors. Detection and quantification of $\mathrm{H}_{2} \mathrm{O}_{2}$ is highly relevant in pharmaceutical, textile, paper, food and chemical industries, where it is used as oxidant for whitening or sterilizing purposes (Zhang and Chen 2017) as well as in medicine, as it plays roles of oxidative stress marker in aging and disease and of defense agent in response to pathogen invasion (Lippert et al. 2011). The reported values of $\mathrm{H}_{2} \mathrm{O}_{2}$ in biological samples cover a broad range of concentrations ( $\mu \mathrm{M}-\mathrm{mM})$ (Forman et al. 2016), demanding for improved and more accurate methods for its detection that are at the same time less susceptible to interfering agents. Among peroxidases, bacterial dye-decolorizing peroxidases (DyPs) reveal a particular potential, due to their broad substrate range, easy genetic manipulation to provide improved variants and high yields (Brissos et al. 2017; Colpa et al. 2014; Mendes et al. 2015a; Rahmanpour et al. 2016), and absence of glycosylation which interferes with DET (Presnova et al. 2000).

DyPs are relatively recently discovered enzymes that share no sequence homology and are structurally unrelated to classical heme peroxidases (Singh and Eltis 2015; Sugano 2009). DyPs lack the highly conserved distal histidine that acts as an acid-base catalyst in the catalytic reaction of classical peroxidases, which implies different mechanistic properties. Instead, they possess strictly conserved distal aspartic acid and arginine that can take up this role (Roberts et al. 2011; Singh et al. 2012; Sugano 2009; van Bloois et al. 2010). The physiological function of DyPs is not fully established. Importantly, they are capable of efficient oxidation of structurally diverse substrates, including synthetic dyes, metals, aromatic sulphides and phenolic and nonphenolic lignin units (Colpa et al. 2014; Mendes et al. 2015b; Santos et al. 2014; Sugano 2009). These bulky substrates bind at the enzyme surface or outside of the heme pocket, and the electrons that are used for the reduction of $\mathrm{H}_{2} \mathrm{O}_{2}$, travel to the ferric $\left(\mathrm{Fe}^{3+}\right)$ heme via long-range electron transfer routes that include surface-exposed tryptophanyl or tyrosyl radicals, similar to lignin (LiP) and versatile (VP) peroxidases (Linde et al. 2015). Systematic studies of peroxidases, and in particular resonance Raman (RR) spectroscopy, established that fivecoordinated high-spin (5cHS) and six-coordinated high-spin $(6 \mathrm{cHS})$ heme species commonly co-exist in the resting states of bacterial and plant peroxidases, e.g. cytochrome c peroxidase (CCP), horse radish peroxidase (HRP), soy bean peroxidase (SBP), etc (Smulevich et al. 2005). The unusual quantum spin admixture (5cQS) species, present in e.g. KatG catalase peroxidase (Kapetanaki et al. 2003), was also identified in some DyPs and shown to be capable of $\mathrm{H}_{2} \mathrm{O}_{2}$ binding and reduction (Sezer et al. 2012a; Sezer et al. 2013; Todorovic et al. 2015). 
Active site structure of immobilized heme enzymes, which is relevant for the $3^{\text {rd }}$ generation bioelectronic devices, often differs from that in solution due to immobilization-induced structural alterations, which inevitably also alter the catalytic properties of the enzyme (Todorovic et al. 2006). To that end, surface enhanced RR (SERR) spectroscopy sensitively probes the spin and oxidation state, and axial coordination pattern of the heme cofactor of peroxidases immobilized on biocompatible plasmonic silver (Ag) supports. The metal that provides the surface enhancements of RR signals of the immobilized enzyme (giving origin to SERR) can furthermore serve as an electrode, allowing for monitoring the enzyme structure in an electrochemical setup (Ly et al. 2011; Murgida and Hildebrandt 2001, 2004; Sezer et al. 2012b).

We have previously demonstrated that wild-type (wt) PpDyP, unlike DyPs from other sources, can be immobilized on biocompatible Ag electrodes under conditions in which the enzyme i) retains structural integrity, ii) reveals efficient DET with the electrode and iii) exhibits electrocatalytic $\mathrm{H}_{2} \mathrm{O}_{2}$ reduction (Sezer et al. 2012a). These are actually the main issues that impede faster advancement of construction of the $3^{\text {rd }}$ generation biosensors in general (Bollella and Gorton 2018), despite the many advantages that they offer, such as selectivity and a simplified electrochemical reaction scheme due to the lack of additional reagents. Here we explore in detail wt PpDyP and its variants that show improved catalytic properties and stability, as biocatalysts for development of electrochemical $\mathrm{H}_{2} \mathrm{O}_{2}$ biosensors. The variants are obtained by directed evolution (DE), which represents the most efficient method for tailoring PpDyP for desired properties (Brissos et al. 2017). We successively apply several levels of criteria to discriminate among the biocatalysts based on their structure and catalytic performance in solution and immobilized states, and identify the best candidate for construction of the $3^{\text {rd }}$ generation PpDyP based $\mathrm{H}_{2} \mathrm{O}_{2}$ biosensor.

\section{Experimental}

\subsection{Enzyme expression and purification}

Cloning, overexpression and purification of wt and evolved variant PpDyPs was performed in E. coli following previously optimized procedures (Brissos et al. 2017; Santos et al. 2014). The DE variants were generated by random mutagenesis using error prone PCR. Screening and selection of evolved variants was performed in 96-well plates; the activity of crude extracts was determined in the presence of 2,6-dimethoxyphenol (DMP). The variant with the highest stability was chosen to be the parent for the next generation, namely $6 \mathrm{E} 10 \rightarrow 29 \mathrm{E} 4 \rightarrow 25 \mathrm{~F} 6$ (cf. detailed experimental information regarding the cloning, expression and purification of PpDyP variants in Supplementary Material). 


\subsection{Apparent steady-state kinetic analysis}

Enzymatic activities of wt and variant PpDyPs were monitored using either a Nicolet Evolution 300 spectrophotometer from Thermo Industries (Madison, USA) or a Synergy2 microplate reader (BioTek, Vermont, USA) at $25^{\circ} \mathrm{C}$. The optimal $\mathrm{pH}\left(\mathrm{pH}_{\mathrm{opt}}\right)$ was determined by monitoring

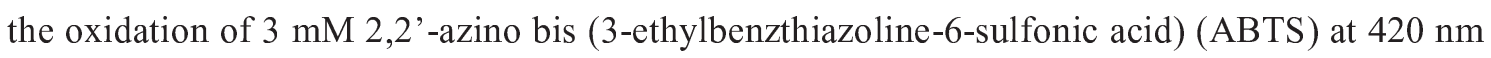
in the presence of $1 \mathrm{mM} \mathrm{H}_{2} \mathrm{O}_{2}$ at $25^{\circ} \mathrm{C}$ using Britton-Robinson buffer $(100 \mathrm{mM}$ phosphoric acid, $100 \mathrm{mM}$ boric acid, and $100 \mathrm{mM}$ acetic acid mixed with $\mathrm{NaOH}$ to the desired $\mathrm{pH}$ in the range 2 - 11). The kinetic parameters for $\mathrm{H}_{2} \mathrm{O}_{2}(0.005-5 \mathrm{mM})$ were measured in the presence of $3 \mathrm{mM}$ $\operatorname{ABTS}\left(\varepsilon_{420 \mathrm{~mm}}=36,000 \mathrm{M}^{-1} \mathrm{~cm}^{-1}\right)$ in $100 \mathrm{mM}$ sodium acetate, at the $\mathrm{pH}_{\mathrm{opt}}$ of the enzymes (Brissos et al. 2017). Kinetic data was fitted directly using the Michaelis-Menten equation or the equation for non-linear curve that fits enzyme kinetics affected by substrate inhibition $(\mathrm{v}=$ $\left.\mathrm{V}_{\max }[\mathrm{S}] /\left(K_{M}+[\mathrm{S}]\left(1+[\mathrm{S}] / K_{i}\right)\right)\right)$ (Origin software).

\subsection{Enzyme stability assays}

Thermal inactivation assays were performed as previously described (Santos et al. 2014). In brief, enzyme solutions were incubated at $60^{\circ} \mathrm{C}$ in $20 \mathrm{mM}$ Tris- $\mathrm{HCl}$ buffer, $\mathrm{pH} \mathrm{7.6}$, and at fixed time intervals, sample aliquots were withdrawn and tested for activity following DMP oxidation (at $468 \mathrm{~nm}$ ) at $25^{\circ} \mathrm{C}$. Residual activities $\left(A_{t} / A_{0}\right.$, where $A_{t}$ is the activity measured at time $t$ and $A_{0}$ is the initial activity at $t=0$ ) were plotted versus the incubation time. Inactivation constants $k_{\text {in }}$ were obtained by linear regression of (ln activity) versus $t$. The half-life value of thermal inactivation $\mathrm{t}_{1 / 2}$ was calculated using $\mathrm{t}_{1 / 2}=\ln 2 / k_{\text {in }}$.

\subsection{Bioelectrode preparation}

The Ag ring electrodes (geometrical area $0.7 \pm 0.05 \mathrm{~cm}^{2}$ ) were prepared as described previously (Murgida and Hildebrandt 2001; Sezer et al. 2012a; Wackerbarth et al. 1999). In brief, the SERR-active Ag electrodes were incubated overnight in SAM solution, containing $1 \mathrm{mM}$ amino-octanethiol (AOT) and $3 \mathrm{mM}$ mercapto-hexanol (MOH) in ethanol. Gold electrodes $(\varnothing 2$ $\mathrm{mm}, \mathrm{BASi}$ ) were polished in $1,0.3$ and $0.05 \mu \mathrm{m}$ (Buehler) alumina slurry, sonicated in deionized water and incubated in SAM solution overnight (vide supra). The SAM coated electrodes were then rinsed with buffer and immersed into a solution containing $0.2 \mu \mathrm{M}$ of the enzymes (in $12.5 \mathrm{mM}$ potassium phosphate buffer solution at $\mathrm{pH} 7.0$, with $12.5 \mathrm{mM} \mathrm{K}_{2} \mathrm{SO}_{4}$ ) for $30 \mathrm{~min}$, prior to measurements. For stability assays, the electrodes were stored in buffer at $4^{\circ} \mathrm{C}$.

\subsection{Spectroscopy}

RR and SERR spectra were acquired with Raman spectrometer (Jobin Yvon LabRam 800 HR) with a back-illuminated CCD detector cooled by liquid nitrogen; an Olympus 20x objective was 
used for laser focusing onto the sample and light collection in the backscattering geometry. The $413 \mathrm{~nm}$ line from a Krypton ion laser (Coherent Innova 300c) was used as the excitation source. The RR spectra of $100-200 \mu \mathrm{M}$ enzyme were measured in a rotating cuvette (Hellma). The potential-dependent SERR experiments were performed using a home-built spectroelectrochemical cell equipped with a three-electrode arrangement: the SAM/enzyme modified $\mathrm{Ag}$ working electrode, an $\mathrm{Ag} / \mathrm{AgCl}(3 \mathrm{M}, \mathrm{KCl})$ reference electrode (WPI) and a platinum wire counter electrode (Radiometer). Electrode potentials were controlled using a Princeton Applied Research 263A potentiostat. The experiments were carried out in supporting electrolyte $(12.5 \mathrm{mM}$ potassium phosphate buffer solution at $\mathrm{pH} 7.0$, containing $12.5 \mathrm{mM}$ $\mathrm{K}_{2} \mathrm{SO}_{4}$ ). The working electrodes were kept under constant rotation $(3000 \mathrm{rpm})$ to prevent prolonged exposure of individual enzyme molecules to laser irradiation. The laser power was 3 $\mathrm{mW}$ and accumulation times were 30 and $20 \mathrm{~s}$ in SERR and RR experiments, respectively; typically 4-10 spectra were co-added in each measurement to improve signal to noise $(\mathrm{S} / \mathrm{N})$ ratio.

\subsection{Electrochemistry}

The bioelectrodes were characterized at room temperature by cyclic voltammetry (CV) and chronoamperometry, performed in the SERR spectroelectrochemical cell (cf. above). Prior to measurements, the supporting electrolyte $(10 \mathrm{~mL})$ was deoxygenated by bubbling argon for 20 min; the cell was maintained under argon atmosphere during the course of the experiment. Cyclic voltammograms were recorded in the range of 0.3 to $-0.15 \mathrm{~V}$ at a scan rate of $50 \mathrm{mV} \cdot \mathrm{s}^{-1}$. The chronoamperograms (I vs. t) were performed at an applied potential of $0.1 \mathrm{~V}$ and under a rotation speed of $2600 \mathrm{rpm}$. Response of the bioelectrode to $\mathrm{H}_{2} \mathrm{O}_{2}$ was evaluated by successive injections of previously deoxygenated stock solutions to the cell. The catalytic currents $\left(\mathrm{I}_{\mathrm{cat}}\right)$ were corrected by subtracting the current measured in the absence of substrate. Concentration of $\mathrm{H}_{2} \mathrm{O}_{2}$ in stock solutions was determined spectrophotometrically using a molar absorption coefficient of $43.6 \mathrm{M}^{-1} \cdot \mathrm{cm}^{-1}$ at $240 \mathrm{~nm}$ (Hildebrandt and Roots 1975). Kinetic data were fit either with the Michaelis-Menten equation or Michaelis-Menten affected by substrate inhibition $\left(\mathrm{I}_{\text {cat }}=\mathrm{I}_{\max }[\mathrm{S}] /\left(\mathrm{K}_{\mathrm{M}}+[\mathrm{S}] /\left(1+[\mathrm{S}] / \mathrm{K}_{\mathrm{S}}\right)\right)\right)$. All potentials are quoted vs. the normal hydrogen electrode (NHE) (+ $0.205 \mathrm{~V}$ vs. Ag/AgCl, $3 \mathrm{M} \mathrm{KCl})$.

\section{Results and Discussion}

\subsection{Directed evolution PpDyP variants with improved properties}

The 6E10 PpDyP variant, evolved after three rounds of DE, exhibits a 100-fold improved catalytic efficiency for phenolic substrate DMP and resistance to $\mathrm{H}_{2} \mathrm{O}_{2}$ inactivation but 
nevertheless limited thermo-stability (Brissos et al. 2017). It harbors three mutations (E188K, A142V and H125Y) at the surface of the enzyme, in the second shell of the heme cavity. Using $6 \mathrm{E} 10$ as parent, the 29E4 variant showing $\sim 5$-fold higher thermo-stability, was identified among 4000 clones. Its sequence reveals the loss of A142V mutation present in 6E10 (Fig. $\mathrm{S} 1)$. In the following round of DE, using $29 \mathrm{E} 4$ as parent, a hit 25F6 was identified, showing 1.7fold higher thermo-stability than 29E4. It carries A142V and G129D mutations (Fig. S1). The catalytic properties of the purified variants, determined at the respective $\mathrm{pH}_{\text {opt }}$ for $\mathrm{H}_{2} \mathrm{O}_{2}$ substrate, reveal that elimination of the A142V in $29 \mathrm{E} 4$ variant results in a catalytic efficiency $\left(\left(k_{\mathrm{cat}} / K_{M}\right)\right.$ similar to that of 6E10. A reintroduction of this mutation, together with the G129D, in $25 \mathrm{~F} 6$ variant results in one order of magnitude lower $k_{\text {cat }} / K_{M}$ (Table 1) (Brissos et al. 2017). The thermal inactivation profiles, obtained from kinetic stability assays performed at $60^{\circ} \mathrm{C}$, indicate that 29E4 and 25F6 variants have a higher half-life inactivation $\left(43 \pm 11 \mathrm{~min}^{-1}\right.$ and $36 \pm 9$ $\mathrm{min}^{-1}$, respectively) than $6 \mathrm{E} 10$ and $\mathrm{wt}\left(7 \pm 1 \mathrm{~min}^{-1}\right.$ and $15 \pm 2 \mathrm{~min}^{-1}$ respectively) (Fig. S2).

Table 1 - Kinetic and analytical characterization of wt PpDyP and variants in solution and immobilized state. Apparent steady-state kinetic parameters for reduction of $\mathrm{H}_{2} \mathrm{O}_{2}$ were determined in solution using ABTS as reducing substrate at $25^{\circ} \mathrm{C}$ and at the $\mathrm{pH}_{\text {opt }}$ of the enzymes. The response of PpDyP/SAM/Ag electrodes to $\mathrm{H}_{2} \mathrm{O}_{2}$ was determined at room temperature and $\mathrm{pH}$ 7.0. Limit of detection (LOD) was determined at $\mathrm{S} / \mathrm{N}$ of 3 . Reproducibility is represented as the variation of catalytic current at $50 \mu \mathrm{M} \mathrm{H}_{2} \mathrm{O}_{2}$ for different electrode preparations ( $\mathrm{n}=6-8)$. nd - not detected; * - taken from (Santos et al. 2014).

\begin{tabular}{|c|c|c|c|c|c|}
\hline & PpDyP & wt & $6 \mathrm{E} 10$ & 29E4 & $25 \mathrm{~F} 6$ \\
\hline & mutations & - & $\begin{array}{l}\text { E188K/A142V/ } \\
\text { H125Y }\end{array}$ & E188K/H125Y & $\begin{array}{l}\text { E188K/A142V/ } \\
\text { H125Y/G129D }\end{array}$ \\
\hline \multirow{5}{*}{$\stackrel{\text { อ }}{\stackrel{\Xi}{\mathrm{E}}}$} & pH & $4.3^{*}$ & 5.5 & 4.5 & 5.5 \\
\hline & $\mathbf{K}_{\mathbf{M}}^{\text {app }}(\mu \mathbf{M})$ & $60 \pm 10^{*}$ & $57 \pm 18$ & $87 \pm 11$ & $268 \pm 23$ \\
\hline & $\mathbf{k}_{\text {cat }}\left(\mathrm{s}^{-1}\right)$ & $23 \pm 2 *$ & $13 \pm 2$ & $43 \pm 1$ & $9 \pm 1$ \\
\hline & $\mathbf{k}_{\mathrm{cat}} / \mathbf{K}_{\mathrm{M}}\left(\mathbf{M}^{-1} \cdot \mathbf{s}^{-1}\right)$ & $(4 \pm 1) \times 10^{5 *}$ & $(2 \pm 1) \times 10^{5}$ & $(5 \pm 1) \times 10^{5}$ & $(3 \pm 1) \times 10^{4}$ \\
\hline & $\mathbf{K}_{\mathbf{i}}(\mathbf{m M})$ & $0.7 \pm 0.1^{*}$ & nd & $0.9 \pm 0.1$ & nd \\
\hline \multirow{8}{*}{ 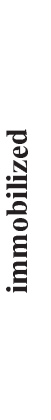 } & pH & 7.0 & 7.0 & 7.0 & 7.0 \\
\hline & $\mathrm{K}_{\mathrm{M}}^{\mathrm{app}}(\mathrm{mM})$ & $0.43 \pm 0.02$ & $0.18 \pm 0.01$ & $0.22 \pm 0.03$ & $0.14 \pm 0.03$ \\
\hline & $J_{\max }\left(\mu \mathbf{A} \cdot \mathbf{c m}^{-2}\right)$ & $-832 \pm 19$ & $-222 \pm 6$ & $-550 \pm 23$ & $-65 \pm 7$ \\
\hline & $\mathbf{K}_{\mathbf{i}}(\mathbf{m} \mathbf{M})$ & nd & $3.5 \pm 0.3$ & nd & $1.1 \pm 0.2$ \\
\hline & Linear Range $(\mu \mathbf{M})$ & $1-200$ & $1-50$ & $1-150$ & $1-50$ \\
\hline & LOD $(\mu \mathrm{M})$ & 3.6 & 1.5 & 3.2 & 3.6 \\
\hline & $\begin{array}{l}\text { Sensitivity } \\
\left(\mathbf{A} \cdot \mathbf{M}^{-1} \cdot \mathbf{c m}^{-2}\right)\end{array}$ & $1.31 \pm 0.03$ & $0.98 \pm 0.02$ & $1.38 \pm 0.03$ & $0.35 \pm 0.02$ \\
\hline & Reproducibility & $97 \%$ & $86 \%$ & $96 \%$ & $89 \%$ \\
\hline
\end{tabular}




\subsection{Immobilized PpDyPs}

Wt PpDyP and variants were electronically coupled to biocompatible AOT/MOH (1:3) coated metal electrodes and evaluated as platforms for development of the $3^{\text {rd }}$ generation biosensors. The active site structures of the immobilized enzymes were probed by SERR spectroscopy. The comparison of RR spectra of the enzymes in solution and the respective SERR spectra measured upon immobilization on modified nanostructured Ag electrodes allow for the detection of the eventual immobilization-induced structural changes (Ly et al. 2011; Murgida and Hildebrandt 2004; Sezer et al. 2012b; Todorovic et al. 2006; Todorovic et al. 2008). The high frequency region of SERR spectra of the wt and variant PpDyPs reveals the presence of multiple heme sub-states (Fig. 1 and S3b). Two major heme species co-exist in the spectra of the 6E10, 29E4 and $25 \mathrm{~F} 6$ variants, which we attribute to 5 -coordinated high-spin $(5 \mathrm{cHS})$ and 5 -coordinated quantum mechanically mixed-spin (5cQS) species (Sezer et al. 2012a; Sezer et al. 2013). This is particularly evident from the analysis of the $v_{3}$ marker band, sensitive to heme coordination and spin states, that displays two bands centered at 1491 and $1500 \mathrm{~cm}^{-1}$, originating from $5 \mathrm{cHS}$ and 5cQS respectively, Fig. 1.

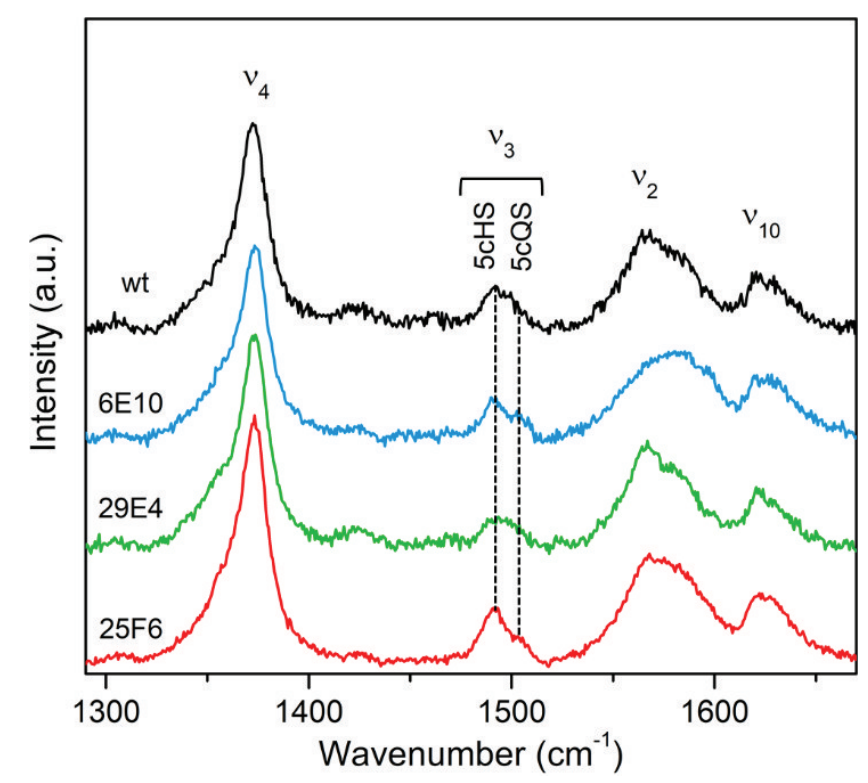

Fig. 1 - High frequency region of SERR spectra of wt, 6E10, 29E4 and 25F6 PpDyPs attached to SAM coated Ag electrodes. Measurements were performed at open circuit potential (ca. 0.29 V). Spectra were acquired with $413 \mathrm{~nm}$ excitation at RT, with $3 \mathrm{~mW}$ laser power and $30 \mathrm{~s}$ accumulation time.

A comparison of RR with SERR spectra indicates no major alterations of the oxidation or coordination state of the heme or appearance of new bands in the SERR spectra, Fig S3a. A deconvolution of SERR spectra reveals a presence of the same heme species detected in RR spectra, but with altered relative abundance, Fig. S3b and Table S1; the 5cHS state becomes 
dominant in the immobilized enzymes. We observe approx. $3 \mathrm{~cm}^{-1}$ upshift of $v_{3}$ (5cQS) modes in SERR spectra of 6E10 and 25F6 PpDyPs, which in the case of some heme proteins could be indicative of formation of 6cLS population. Nevertheless, the $v_{3}(6 \mathrm{cLS})$ is in DyPs expected at much higher frequencies (Sezer et al. 2012a; Sezer et al. 2013). We attribute these findings to different selection rules for RR and SERR effects and / or possibly non-uniform orientation of the attached enzyme to the electrode (Bernad et al. 2004; Kanger and Otto 2003; Todorovic et al. 2012). It is noteworthy that the mutations do not affect the enzyme's active site structure, since the same spin populations, with the similar relative abundance are observed in RR spectra of the wt PpDyP and variants (Fig. S3a, lower traces, and Table S1). This can be rationalized in terms of the relative positions and the nature of the amino acid substitutions (Brissos et al. 2017) (Fig. S1).

In the next step, we probed the redox behavior of PpDyPs attached to AOT/MOH coated $\mathrm{Ag}$ electrodes. The SERR spectra of the immobilized enzymes were measured at poised electrode potentials in 0.3 and $-0.3 \mathrm{~V}$ interval (Fig. S4). The potential-dependent SERR spectra show that PpDyPs can be readily reduced or oxidized in the immobilized state, as indicated by the characteristic shifts of heme redox state sensitive marker bands (e.g. $v_{4}$ and $v_{3}$ ). The redox reaction is fully reversible (Fig. S4, traces a and h); the immobilized enzymes can withstand multiple redox cycles without apparent denaturation, revealing efficient and reversible heterogeneous ET. The SERR signal intensity nevertheless decreases after extended exposure of the enzymes to negative potentials, implying reduction- or potential-induced desorption of the enzymes, which must be taken into consideration in further applications. Altogether, we demonstrate that the active site architecture of PpDyP variants developed by DE does not differ from that of the wt. More importantly for the development of DyP based biosensors, the enzymes' active site structure remains intact upon immobilization. Therefore, we can conclude that at this point that wt PpDyP and all three evolved variants appear to be promising candidates for the development of DyP based sensors, as the respective active site structures and stability are preserved upon immobilization, and they exhibit efficient and reversible ET.

\subsection{PpDyP-based bioelectrodes for electrochemical biosensor development}

Once the preservation of the native structure of immobilized PpDyPs is ensured, as established by SERR spectroscopy, the electrocatalytic properties of PpDyP/SAM/Ag constructs were probed by $\mathrm{CV}$. Upon addition of $\mathrm{H}_{2} \mathrm{O}_{2}$ to the SERR cell, the cathodic current increases due to the catalytic reduction by the enzymes attached to the working electrodes, Fig. S5a. We attribute these catalytic currents to the formation compound I (i.e. catalytic intermediate $\left[\mathrm{Fe}^{4+}=\mathrm{O}\right]^{+\bullet}$ ) that is in PpDyP stabilized upon reaction of the ferric enzyme with $\mathrm{H}_{2} \mathrm{O}_{2}$, which is subsequently 
reduced by the electrode (Sezer et al. 2012a; Todorovic et al. 2015). Note that non-catalytic redox peaks could not be observed in the cyclic voltammograms, most likely due to insufficient amount of the enzyme on the electrode surface.

The choice of the electrode support. Both Ag and Au electrodes were tested. Ag substrates are required for surface enhancement of the RR signal (vide supra) in SERR experiments, but they have limited working potential window, defined by the oxidation of the $\mathrm{Ag}$ at $0.3 \mathrm{~V}$ and reductive desorption of the SAM below $-0.34 \mathrm{~V}$ (Munakata et al. 2004). For that reason the negative current is already present at the start of the scan $(0.3 \mathrm{~V})$, Fig. S5a. Au electrodes allow for application of a wider potential window (up to $0.9 \mathrm{~V}$ ). $\mathrm{PpDyP} / \mathrm{SAM} / \mathrm{Au}$ electrodes show a typical catalytic shape current-potential curve in the presence of $\mathrm{H}_{2} \mathrm{O}_{2}$. The cathodic current peak at ca. $0.83 \mathrm{~V}\left(10 \mu \mathrm{M} \mathrm{H}_{2} \mathrm{O}_{2}\right)$ shifts to lower values as the substrate concentration is increased, Fig S5b. The catalytic current densities obtained at the PpDyP/SAM/Ag electrode are one order of magnitude higher than those measured with the Au counterparts; the modified Ag electrodes were therefore selected for further studies.

The choice of immobilized enzyme, wt vs. variants. The response of wt, 6E10, 29E4 or 25F6 electrodes to $\mathrm{H}_{2} \mathrm{O}_{2}$ was further characterized by chronoamperometry at a potential of $0.1 \mathrm{~V}$, at which direct non-enzymatic reduction of $\mathrm{H}_{2} \mathrm{O}_{2}$ by the electrode is negligible; both $\mathrm{Ag}$ and $\mathrm{Au}$ electrodes show catalytic currents close to maximum at this potential, Fig. S5. The amperometric response recorded upon successive injections of deoxygenated stock solution of $\mathrm{H}_{2} \mathrm{O}_{2}$ to the cell ( $1 \mu \mathrm{M}-2 \mathrm{mM}$ final concentration) reveals the stepwise increase of the catalytic current at very short response times $(<2 \mathrm{~s})$, indicative of efficient heterogeneous ET (Fig. 2).

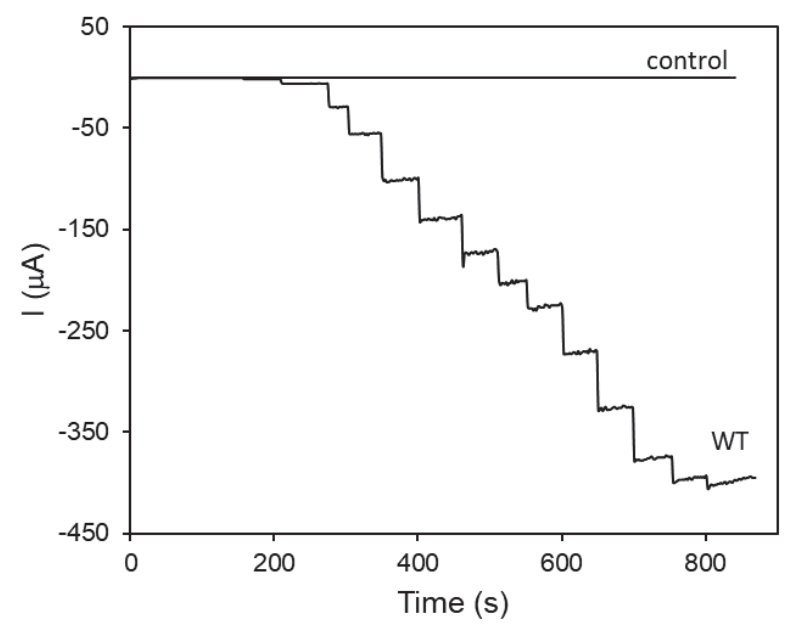

Fig. 2 - Amperometric response of SAM/Ag (control) and wt PpDyP/SAM/Ag electrodes to increasing

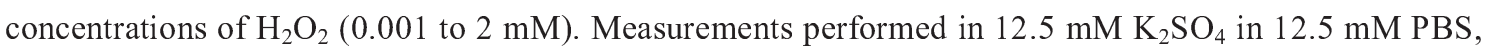
$\mathrm{pH} 7.0$, at an applied potential of $0.1 \mathrm{~V}$. The electrode was rotated at $2600 \mathrm{rpm}$ to minimize the effect of substrate mass transport to the immobilized enzyme. 
Control experiments performed with SAM/Ag electrodes without attached enzyme show a negligible increase of cathodic current upon addition of $\mathrm{H}_{2} \mathrm{O}_{2}$, about $0.2 \%$ of the current measured for wt PpDyP in the presence of $200 \mu \mathrm{M} \mathrm{H}_{2} \mathrm{O}_{2}$. The plots of catalytic current ( $\left.\mathrm{I}_{\text {cat }}\right) \mathrm{vs}$. substrate concentration, measured for all $\mathrm{PpDyP} / \mathrm{SAM} / \mathrm{Ag}$ electrode constructs show a distinct dependence for the studied enzymes, as depicted by electrochemical Michaelis-Menten equation fit to the data, Fig. 3a (Monteiro and Almeida 2019).
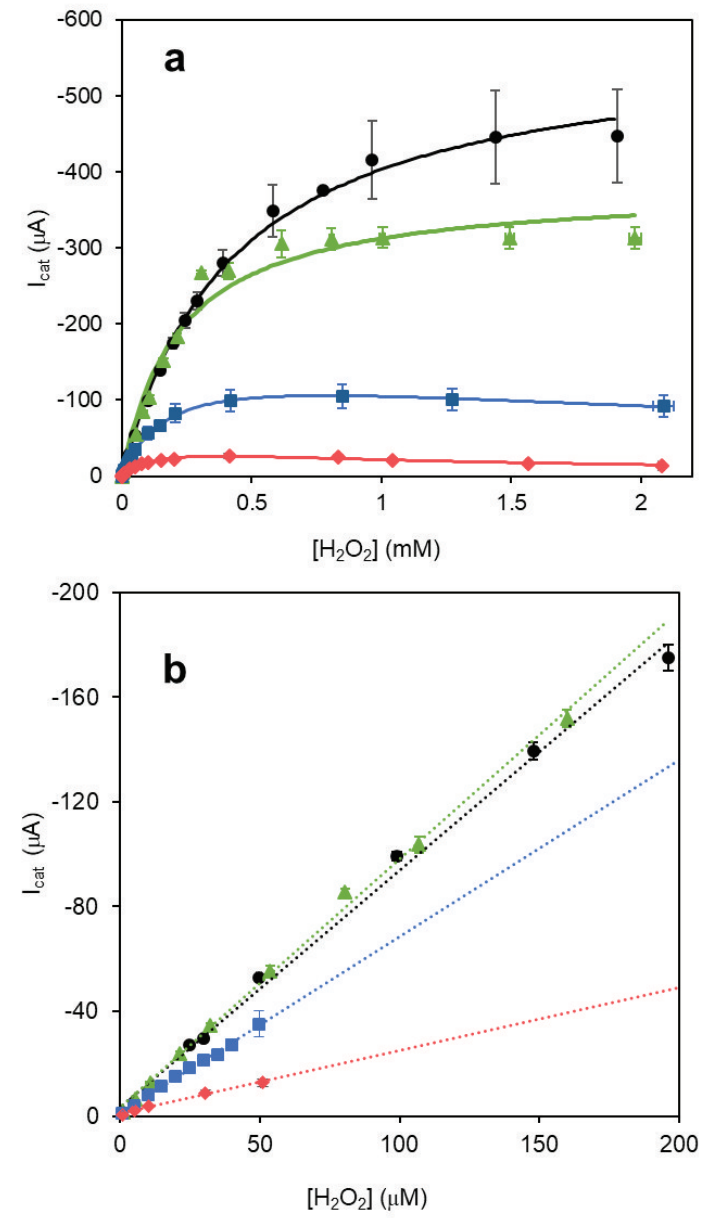

Fig. 3 - a) Michaelis-Menten plots of catalytic currents vs. $\mathrm{H}_{2} \mathrm{O}_{2}$ concentration for wt (black circles), $6 \mathrm{E} 10$ (blue squares), 29E4 (green triangles) and 25F6 PpDyP/SAM/Ag electrodes (red diamond). The relative standard deviations (RSD) vary between 2 - 6\% for wt and 29E4 and 7 - 15\% for $6 \mathrm{E} 10$ and 25F6 electrodes; wt displays ca. $15 \%$ RSD for $\left[\mathrm{H}_{2} \mathrm{O}_{2}\right]>1 \mathrm{mM}$; b) Linear dependence of the catalytic current on $\mathrm{H}_{2} \mathrm{O}_{2}$ concentration ( $\mathrm{n}=6-8$ ), with slope and $\mathrm{r}^{2}$ of $1.31 \mathrm{~A} \cdot \mathrm{M}^{-1} \cdot \mathrm{cm}^{-2}$ and $0.996(\mathrm{wt}), 0.98 \mathrm{~A} \cdot \mathrm{M}^{-1} \cdot \mathrm{cm}^{-2}$ and $0.996(6 \mathrm{E} 10), 1.38 \mathrm{~A} \cdot \mathrm{M}^{-1} \cdot \mathrm{cm}^{-2}$ and $0.997(29 \mathrm{E} 4)$ and $0.35 \mathrm{~A} \cdot \mathrm{M}^{-1} \cdot \mathrm{cm}^{-2}$ and $0.989(25 \mathrm{~F} 6)$.

The wt and 29E4 bioelectrodes reach a plateau for concentrations of $\mathrm{H}_{2} \mathrm{O}_{2}$ higher than $0.4 \mathrm{mM}$, which is indicative of a Michaelis-Menten-type enzyme kinetics (Fig. 3a). The apparent Michaelis-Menten constant $\left(\mathrm{K}_{\mathrm{M}}{ }^{\text {app }}\right)$ and maximum current density at saturating substrate 
concentration $\left(\mathrm{J}_{\max }\right)$ values are lower for the $29 \mathrm{E} 4\left(0.14 \mathrm{mM}\right.$ and $\left.-550 \mu \mathrm{A} \cdot \mathrm{cm}^{-2}\right)$ than for the wt PpDyP $\left(0.43 \mathrm{mM}\right.$ and $\left.-832 \mu \mathrm{A} \cdot \mathrm{cm}^{-2}\right)$, Table 1 , indicating a higher affinity for $\mathrm{H}_{2} \mathrm{O}_{2}$ but slightly lower activity of the immobilized 29E4. In solution, the analogous $\mathrm{K}_{\mathrm{i}}$ and $\mathrm{K}_{\mathrm{M}}$ values are $0.7 \mathrm{mM}$ and $60 \mu \mathrm{M}$ for wt PpDyP and $0.9 \mathrm{mM}$ and $87 \mu \mathrm{M}$ for $29 \mathrm{E} 4$, while $\mathrm{k}_{\mathrm{cat}} / \mathrm{K}_{\mathrm{M}}$ are nearly identical (4 and $5 \times 10^{5} \mathrm{M}^{-1} \mathrm{~s}^{-1}$, respectively). This is consistent with substrate inhibited enzyme kinetics of wt and 29E4 PpDyPs in solution and slightly higher affinity of the former for $\mathrm{H}_{2} \mathrm{O}_{2}$. The catalytic currents of immobilized $6 \mathrm{E} 10$ and 25F6 are lower $\left(-220\right.$ and $\left.-65 \mu \mathrm{A} \cdot \mathrm{cm}^{-2}\right)$ and decrease with increasing $\mathrm{H}_{2} \mathrm{O}_{2}$ concentration (above 0.4 and $0.8 \mathrm{mM}$ respectively). In solution, the $6 \mathrm{E} 10$ and $25 \mathrm{~F} 6$ variants do not show substrate inhibition; the respective $\mathrm{K}_{\mathrm{M}}$ and $\mathrm{k}_{\mathrm{cat}} / \mathrm{K}_{\mathrm{M}}$ values are $57 \mu \mathrm{M}$ and $2 \times 10^{5} \mathrm{M}^{-1} \mathrm{~s}^{-1}$ for the former and $268 \mu \mathrm{M}$ and $3 \times 10^{4} \mathrm{M}^{-1} \mathrm{~s}^{-1}$ for the latter. It appears that the decrease in electrocatalytic current can be related to the A142V mutation that both $6 \mathrm{E} 10$ and $25 \mathrm{~F} 6$ carry. The absence of $\mathrm{H}_{2} \mathrm{O}_{2}$ inhibition in solution was rationalized in terms of conformational rearrangements in the heme cavity caused by A142V substitution, which leads to shielding of sensitive amino acids from $\mathrm{H}_{2} \mathrm{O}_{2}$ induced oxidation (Brissos et al. 2017). This behavior was not translated to the immobilized state, since the kinetic parameters of the single A142V variant are comparable to those of immobilized 6E10 and 25F6 (Fig. S6). An improved performance of wt and 29E4 PpDyPs is nevertheless clearly evident upon immobilization of these enzymes. The discrepancy between enzymes' behavior in solution and immobilized states can be tentatively attributed to the fact that the attachment of an enzyme to a solid electrode support alters its rotational freedom and may affect substrate accessibility. Furthermore, electrons for the catalytic reaction are provided by an electrode, and the ET pathways are most likely different than in solution, in which the apparent steady-state kinetic parameters for reduction of $\mathrm{H}_{2} \mathrm{O}_{2}$ are determined using ABTS as reducing substrate. An additional variable is $\mathrm{pH}$; envisaging broad range of physiologically relevant applications, all measurements reported in this work were performed at $\mathrm{pH} \mathrm{7,} \mathrm{while} \mathrm{the} \mathrm{solution} \mathrm{measurements}$ refer to acidic $\mathrm{pH}_{\mathrm{opt}}$ for each enzyme. It is noteworthy that the affinity for $\mathrm{H}_{2} \mathrm{O}_{2}$ of all four DyPs decreases in the immobilized state, as the $\mathrm{K}_{\mathrm{M}}$ values are 2 to 5 times higher for the adsorbed enzymes than in solution (Brissos et al. 2017; Mendes et al. 2015a; Sezer et al. 2012a). This behavior is commonly observed for enzymes immobilized on electrode surfaces, and is typically attributed to the limited diffusion of the substrate to the enzyme's active site (Monteiro and Almeida 2019).

The response of the wt PpDyP bioelectrode to $\mathrm{H}_{2} \mathrm{O}_{2}$ is linear from $1-200 \mu \mathrm{M}$; in the case of 29E4 it is slightly lower, $1-150 \mu \mathrm{M}$. The sensitivity, determined by the slope of the calibration curve, and the limit of detection, estimated at $\mathrm{S} / \mathrm{N}$ of three, are $1.31 \mathrm{~A} \cdot \mathrm{M}^{-1} \cdot \mathrm{cm}^{-2}$ and $3.6 \mu \mathrm{M}$, respectively for wt PpDyP and similarly, $1.38 \mathrm{~A} \cdot \mathrm{M}^{-1} \cdot \mathrm{cm}^{-2}$ and $3.2 \mu \mathrm{M}$ for $29 \mathrm{E} 4$ bioelectrode, Table 1. The analytical performance of the $6 \mathrm{E} 10$ and $25 \mathrm{~F} 6$ electrodes is poorer, as expected 
given their kinetic behavior in the immobilized state (vide supra). The sensor-to-sensor reproducibility, determined by measuring the catalytic current of 6 to 8 bioelectrodes in $50 \mu \mathrm{M}$ $\mathrm{H}_{2} \mathrm{O}_{2}$, varies between $96-97 \%$ for the wt and 29E4 (cf. Table 1). The 6E10 and 25F6 bioelectrodes display higher current variations and lower reproducibility. Since these two variants are in addition prone to substrate inhibition, we can conclude that they are not appropriate for biosensor development.

Table 2 - Analytical parameters of electrochemical $\mathrm{H}_{2} \mathrm{O}_{2}$ biosensors based on HRP. SWCNT - single walled carbon nanotubes; GC - glassy carbon; OANW - oleylamine-stabilized gold nanowires; C-Dots carbon nanodots; LDHs - layered double hydroxides; 3-CPDS - 3-Carboxypropyldisulfide SAM; G graphite electrode; Pan - polyaniline; MWCNTCOOH - carboxy-functionalized multiwalled carbon nanotube; CNT - Carbon nanotubes; AuNPs - gold nanoparticles; Chit - Chitosan; poly - polymerized; CESM - Carbonized chicken eggshell membrane; TH/SAME - thionine-modified SAM electrode; nano$\mathrm{Au}$ - nano-scaled particulate gold; CCE - carbon ceramic electrode; GNP-TNT - gold nanoparticle dotted $\mathrm{TiO}_{2}$ nanotubes; HIL - hydrophobic ionic liquid; PEGDGE - poly(ethyleneglycol) diglycidyl ether; $[\mathrm{Os}(\mathrm{dmp}) \mathrm{PVI}]^{+/ 2+}-$ osmium redox polymer. All values refer to $3^{\text {rd }}$ generation biosensors except for those marked with $*$ which refer to $2^{\text {nd }}$ generation (mediated) biosensors.

\begin{tabular}{|c|c|c|c|c|c|}
\hline Bioelectrode & $\begin{array}{l}\text { LOD } \\
(\mu \mathrm{M})\end{array}$ & $\begin{array}{l}\text { Linear } \\
\text { Range }(\mu \mathbf{M})\end{array}$ & $\begin{array}{l}\text { Response } \\
\text { time (s) }\end{array}$ & $\begin{array}{l}\text { Sensitivity } \\
\left(\mathbf{A} \cdot \mathbf{M}^{-1}\right. \\
\left.\cdot \mathrm{cm}^{-2}\right)\end{array}$ & Reference \\
\hline HRP/DNA-SWCNT/GC & 0.3 & $0.6-1800$ & - & 0.62 & (Zeng et al. 2009) \\
\hline HRP-OANW/Au & 5 & $20-500$ & - & 0.031 & (Koposova et al. 2014) \\
\hline HRP/C-Dots/LDHs/GC & 0.04 & $0.1-23.1$ & - & $0.47 \times 10^{-3}$ & (Wang et al. 2015) \\
\hline $\mathrm{HRP} / 3-\mathrm{CPDS} / \mathrm{Au}$ & - & $100-1000$ & - & $4.24 \times 10^{-4}$ & (Gaspar et al. 2001) \\
\hline $\mathrm{HRP} / \mathrm{G}$ & 0.071 & $0.5-130$ & - & 0.338 & (Gaspar et al. 2000) \\
\hline HRP/Pan/MWCNTCOOH/Au & 86 & $86-10000$ & 2.9 & 0.195 & (Hua et al. 2011) \\
\hline HRP/MWCNTCOOH/Au & 26 & $26-8000$ & 2.3 & 0.175 & (Hua et al. 2011) \\
\hline $\mathrm{Au} / \mathrm{SAM} / \mathrm{HRP} / \mathrm{CNT}$ & 0.02 & $0.107-120$ & - & - & (Kafi et al. 2018) \\
\hline HRP/AuNPs & 0.41 & $0.5-70$ & - & 0.193 & $\begin{array}{l}\text { (Narayanan and } \\
\text { Slaughter 2019) }\end{array}$ \\
\hline HRP/laponite/Chit/GC & 5 & $29-1400$ & 10 & $19.7 \times 10^{-3}$ & (Shan et al. 2010) \\
\hline $\mathrm{HRP} /$ polyAuNPs/Au & 1.5 & $5-1100$ & 8 & $498 \times 10^{-3}$ & (Villalonga et al. 2011) \\
\hline HRP/AuNPs/CESM/GC & 0.3 & $10-2700$ & 3 & - & (Zhang et al. 2015) \\
\hline TH/HRP/SAME/Au* & 40 & $40-100$ & - & $2.5 \times 10^{-3}$ & (Ruan et al. 1998) \\
\hline $\mathrm{HRP} /$ nano-Au/CCE/GC* & 6.1 & $12.2-1100$ & 8 & 0.29 & (Lei et al. 2004) \\
\hline GNP-TNT/HIL/HRP/GC* & 2.2 & $15-750$ & 3 & 0.228 & (Liu et al. 2012) \\
\hline $\mathrm{HRP} / \mathrm{PEGDGE} /[\mathrm{Os}(\mathrm{dmp}) \mathrm{PVI}]^{+/ 2+} / \mathrm{G}^{*}$ & 0.3 & $1-500$ & 3 & 0.297 & (Bollella et al. 2018) \\
\hline
\end{tabular}


A number of features of the wt and 29E4 bioelectrodes are actually remarkable in comparison with examples found in the literature. The immobilized wt and 29E4 PpDyPs perform better than HRP, which was particularly explored for $\mathrm{H}_{2} \mathrm{O}_{2}$ biosensors, and which is used in the only commercially available $\mathrm{H}_{2} \mathrm{O}_{2}$ biosensing device. Wt and 29E4 PpDyP constructs show shorter response time and superior sensitivity in respect to the published enzyme based $\mathrm{H}_{2} \mathrm{O}_{2}$ biosensors, including those that employ nanomaterials that usually display high activities owing to increased loading of enzymes (Table 2). We show that both wt and 29E4 PpDyP have 1.3-1.4 $\mathrm{A} \cdot \mathrm{M}^{-1} \cdot \mathrm{cm}^{-2}$ sensitivity, which is one to four orders of magnitude higher than the values reported in the literature for HRP based bioelectrodes, none of which exceeds $0.6 \mathrm{~A} \cdot \mathrm{M}^{-1} \cdot \mathrm{cm}^{-2}$. The response time of $2 \mathrm{~s}$ is also shorter than in any of the reported HRP based systems. In terms of LOD, wt and 29E4 PpDyP bioelectrodes show an average behavior $(3.6 \mu \mathrm{M})$ as it falls in the middle of 0.02-86 $\mu \mathrm{M}$ range reported for HRP based electrodes (Table 2). Their linear range is on the narrower side (1-200 and 1-150 $\mu \mathrm{M}$ for wt and 29E4 PpDyPs, respectively), while some HRP based systems span over concentrations of 3 orders of magnitude. This is nevertheless not necessarily a drawback as long as it is contemplated in the envisaged applications (vide supra). Taken together, we can conclude that wt PpDyP and 29E4 variant represent promising candidates for the construction of $\mathrm{H}_{2} \mathrm{O}_{2}$ biosensors and they were further tested (vide infra).

Stability of wt and 29E4 PpDyP biosensors. The response stability of the wt and 29E4 PpDyP bioelectrodes was evaluated by measuring catalytic currents in the presence of $50 \mu \mathrm{M} \mathrm{H}_{2} \mathrm{O}_{2}$ in regular time intervals during 1 month period, using electrodes stored at $4^{\circ} \mathrm{C}$ in supporting electrolyte. SERR spectra of stored electrodes reveal no significant changes at the level of enzyme's active site in comparison to that of the freshly immobilized enzyme (i.e. electrode prepared and measured on the same day) (Fig. S7). The shelf-life was evaluated by comparing sets of wt and 29E4 PpDyP bioelectrodes prepared on the same day. Both enzymes retain about $85-95 \%$ of the initial biocatalytic response (measured on day 1) during one month, Fig. 4. However, multiple uses of the same electrode causes an abrupt decrease of the initial activity (Fig. 4 inset), with estimated half-life of 13 hours for wt and 36 hours for 29E4. This could be due to enzyme desorption from the electrode (e.g. washing procedures, application of electrode potentials repeatedly) and / or inactivation owing to exposure to $\mathrm{H}_{2} \mathrm{O}_{2}$ (Todorovic et al. 2015). In fact, we observe that electrode manipulation plays a major role in the loss of the catalytic performance. It is noteworthy that the ring Ag electrodes, used throughout this work, are specially designed for SERR spectroscopy, and are not optimized for multiple usage. Taking this into consideration, together with the good shelf-life of the wt and 29E4 based electrodes, we propose their use for the development of a disposable biosensor. 


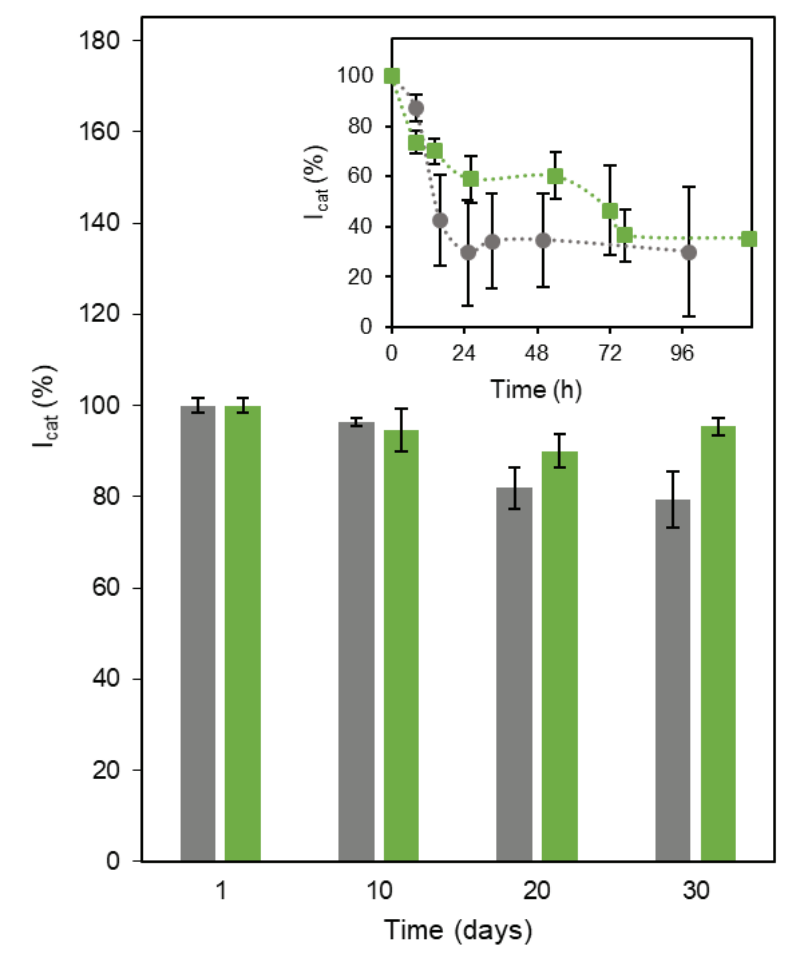

Fig. 4 - Stability of wt (gray) and 29E4 PpDyP/SAM/Ag (green) electrodes response to $\mathrm{H}_{2} \mathrm{O}_{2}$. Relative catalytic current response to $50 \mu \mathrm{M} \mathrm{H}_{2} \mathrm{O}_{2}$, measured on a batch of electrodes prepared on the same day $(\mathrm{n}=16)$, during storage at $4{ }^{\circ} \mathrm{C}$ for 1 month (shelf-life). Inset: relative catalytic current measured using the same electrode $(n=4)$ during a 5 day period.

The selectivity of the wt and 29E4 PpDyP bioelectrodes was further tested in the presence of potential interfering substances, ascorbate, citrate, ethanol, sucrose, glucose and $\mathrm{O}_{2}$, which are likely to be present in real samples. The respective responses were evaluated by a comparison of the catalytic current obtained upon addition of $\mathrm{H}_{2} \mathrm{O}_{2}(10 \mu \mathrm{M}$ final concentration) in the presence or absence of 10 times higher concentration of hypothetical interfering substances. No interference is detected for the compounds tested (Table S2).

\section{Conclusions}

Reliable, fast, sensitive, selective and low-cost $\mathrm{H}_{2} \mathrm{O}_{2}$ sensors are highly sought after for numerous applications. To this end, continuous efforts are being made to explore i) novel biocatalysts with improved stability and catalytic performance, including plant peroxidases (e.g. HRP, tobacco peroxidase and new tropical plant peroxidases), $\mathrm{CcP}$, chloroperoxidase, lactoperoxidase, etc. (Bollella and Gorton 2018); ii) diverse electrode materials and coatings, which ensure high enzyme loading and efficient DET, such as polymers, nanostructures and 
recently reported quantum dots (Wang et al. 2015); and iii) simple and sensitive analytical methods for detection of the catalytic signal. To the best of our knowledge, we report here the first thorough characterization of a $3^{\text {rd }}$ generation electrochemical biosensor for $\mathrm{H}_{2} \mathrm{O}_{2}$ detection based on DyP-type peroxidases with improved properties tailored by directed evolution. We evaluate the analytical performance of the wt PpDyP and three variants in solution and immobilized states and show that two biocatalysts are exceptionally well fit for the envisaged purpose. Both, wt and 29E4 PpDyPs represent excellent candidates for construction of $\mathrm{H}_{2} \mathrm{O}_{2}$ biosensors, as they show superior sensitivity and shorter response times compared to HRP based $\mathrm{H}_{2} \mathrm{O}_{2}$ biosensors reported so far in the literature (Shan et al. 2010; Villalonga et al. 2011; Zhang et al. 2015). They are stable for prolonged periods during storage and are insensitive to the presence of possible interference agents. This makes them remarkably suitable for development of biosensors in disposable, single-use configuration, based on e.g. silver screen-printed electrodes, for a variety of biological applications (Guo 2016; Guo and Ma 2017; Guo et al. 2019).

We highlight the importance of integrated, multidisciplinary approach to simultaneously evaluate the structure and catalytic properties of the enzymes in solution and immobilized state. We demonstrate that the catalytic parameters in solution are not indicative of the enzymes electrocatalytic performance in the immobilized state, which is relevant for the development of the $3^{\text {rd }}$ generation biosensors. A matrix of criteria was necessary to discriminate between the enzymes and allow for a prediction of their potential for the desired application. Surprisingly, preservation of the native structure upon enzyme immobilization, which can be determined by SERR spectroscopy and is the most common determinant for the success or failure of $3^{\text {rd }}$ generation bioelectronics devices (Todorovic et al. 2006), has not provided any insights for differentiation between the wt and variant PpDyPs. The native structure is well preserved upon attachment of all studied enzymes to biocompatible metal supports and only their thorough kinetic and analytical characterization allowed for identification of the best performing biocatalyst. To that end, wt and 29E4 PpDyPs show subtle differences in $\mathrm{H}_{2} \mathrm{O}_{2}$ sensing, which makes them equally suitable for the foreseen application. These enzymes can be further explored for bioelectrocatalysis of other DyP substrates, such as inert environmentally harmful dyes (e.g. phenolic and azo dyes) or lignin related compounds and their valorization, or further improved as $\mathrm{H}_{2} \mathrm{O}_{2}$ biosensors with higher accuracy and reproducibility for clinical or tissue engineering applications. As an additional evident advantage, PpDyP can be easily overexpressed in E. coli and manipulated to produce specific variants by rational design or directed evolution, which offers close to limitless opportunities for tailored applications employing immobilized PpDyP variants. 


\section{Acknowledgements}

The authors thank Sérgio Almeida for assistance in preliminary studies. This work was financially supported by Project LISBOA-01-0145-FEDER-007660 (Microbiologia Molecular, Estrutural e Celular) funded by FEDER funds through COMPETE 2020-Programa Operacional Competitividade e Internacionalização (POCI); by national funds through FCT- Fundação para a Ciência e a Tecnologia (PTDC/BBBEBB/0122/2014, PTDC/BII-BBF/29564/2017 and PTDC/BIA-BFS/31026/2017) and by the Deutsche Forschungsgemeinschaft (DFG, German Research Foundation) under Germany's Excellence Strategy - EXC 2008/1 (UniSysCat) 390540038. We acknowledge support from $\mathrm{TIMB}^{3}$ and B-LigZymes projects, which have received funding from the European Union's Horizon 2020 research and innovation program under grant agreements $\mathrm{N}^{\circ} 810856$ and 824017 , respectively.

\section{References}

Bernad, S., Soulimane, T., Lecomte, S., 2004. J. Raman Spectrosc. 35, 47-54.

Bollella, P., Gorton, L., 2018. Curr. Opin. Electrochem. 10, 157-173.

Bollella, P., Medici, L., Tessema, M., Poloznikov, A.A., Hushpulian, D.M., Tishkov, V.I., Andreu, R., Leech, D., Megersa, N., Marcaccio, M., Gorton, L., Antiochia, R., 2018. Solid State Ionics 314, 178-186.

Brissos, V., Tavares, D., Sousa, A.C., Robalo, M.P., Martins, L.O., 2017. ACS Catal. 7, 34543465.

Colpa, D.I., Fraaije, M.W., van Bloois, E., 2014. J. Ind. Microbiol. Biotechnol. 41, 1-7.

Das, P., Das, M., Chinnadayyala, S.R., Singha, I.M., Goswami, P., 2016. Biosens. Bioelectron. 79, 386-397.

Forman, H.J., Bernardo, A., Davies, K.J.A., 2016. Arch. Biochem. Biophys. 603, 48-53.

Fu, Y., Yang, H., Guo, J., 2019. IEEE Trans. Ind. Inf. 15, 6389-6394.

Gaspar, S., Popescu, I.C., Gazaryan, I.G., Gerardo Bautista, A., Sakharov, I.Y., Mattiasson, B., Csöregi, E., 2000. Electrochim. Acta 46, 255-264.

Gaspar, S., Zimmermann, H., Gazaryan, I., Csöregi, E., Schuhmann, W., 2001. Electroanalysis $13,284-288$.

Guo, J., 2016. Anal. Chem. 88, 11986-11989.

Guo, J., Ma, X., 2017. Biosens. Bioelectron. 94, 415-419.

Hildebrandt, A.G., Roots, I., 1975. Arch. Biochem. Biophys. 171, 385-397.

Hua, M.-Y., Lin, Y.-C., Tsai, R.-Y., Chen, H.-C., Liu, Y.-C., 2011. Electrochim. Acta 56, 94889495. 
Kafi, A.K.M., Naqshabandi, M., Yusoff, M.M., Crossley, M.J., 2018. Enzyme Microb. Technol. $113,67-74$.

Kanger, J.S., Otto, C., 2003. Appl. Spectrosc. 57, 1487-1493.

Kapetanaki, S., Chouchane, S., Girotto, S., Yu, S., Magliozzo, R.S., Schelvis, J.P.M., 2003. Biochemistry 42, 3835-3845.

Koposova, E., Liu, X., Kisner, A., Ermolenko, Y., Shumilova, G., Offenhausser, A., Mourzina, Y., 2014. Biosens. Bioelectron. 57, 54-58.

Lei, C.X., Hu, S.Q., Gao, N., Shen, G.L., Yu, R.Q., 2004. Bioelectrochemistry 65, 33-39.

Linde, D., Pogni, R., Cañellas, M., Lucas, F., Guallar, V., Baratto, M.C., Sinicropi, A., SáezJiménez, V., Coscolín, C., Romero, A., Medrano, F.J., Ruiz-Dueñas, F.J., Martínez, A.T., 2015. Biochem. J. 466, 253-262.

Lippert, A.R., Van de Bittner, G.C., Chang, C.J., 2011. Acc. Chem. Res. 44, 793-804.

Liu, X., Feng, H., Zhang, J., Zhao, R., Liu, X., Wong, D.K.Y., 2012. Biosens. Bioelectron. 32, 188-194.

Ly, H.K., Sezer, M., Wisitruangsakul, N., Feng, J.J., Kranich, A., Millo, D., Weidinger, I.M., Zebger, I., Murgida, D.H., Hildebrandt, P., 2011. FEBS J. 278, 1382-1390.

Mendes, S., Brissos, V., Gabriel, A., Catarino, T., Turner, D.L., Todorovic, S., Martins, L.O., 2015a. Arch Biochem Biophys 574, 99-107.

Mendes, S., Robalo, M.P., Martins, L.O., 2015b. Bacterial Enzymes and Multi-enzymatic Systems for Cleaning-up Dyes from the Environment. In: Singh, S.N. (Ed.), Microbial Degradation of Synthetic Dyes in Wastewaters, Springer International Publishing, Cham, pp. $27-55$

Monteiro, T., Almeida, M.G., 2019. Crit. Rev. Anal. Chem. 49, 44-66.

Munakata, H., Oyamatsu, D., Kuwabata, S., 2004. Langmuir 20, 10123-10128.

Murgida, D.H., Hildebrandt, P., 2001. J. Phys. Chem. B 105, 1578-1586.

Murgida, D.H., Hildebrandt, P., 2004. Acc. Chem. Res. 37, 854-861.

Narayanan, J.S., Slaughter, G., 2019. Bioelectrochemistry 128, 56-65.

Presnova, G., Grigorenko, V., Egorov, A., Ruzgas, T., Lindgren, A., Gorton, L., Börchers, T., 2000. Faraday Discuss. 116, 281-289.

Rahmanpour, R., Rea, D., Jamshidi, S., Fulop, V., Bugg, T.D., 2016. Arch Biochem Biophys 594, 54-60.

Roberts, J.N., Singh, R., Grigg, J.C., Murphy, M.E., Bugg, T.D., Eltis, L.D., 2011. Biochemistry 50, 5108-5119.

Ruan, C., Yang, F., Lei, C., Deng, J., 1998. Anal. Chem. 70, 1721-1725.

Santos, A., Mendes, S., Brissos, V., Martins, L.O., 2014. Appl. Microbiol. Biotechnol. 98, 2053-2065. 
Sezer, M., Genebra, T., Mendes, S., Martins, L.O., Todorovic, S., 2012a. Soft Matter 8, 1031410321.

Sezer, M., Millo, D., Weidinger, I.M., Zebger, I., Hildebrandt, P., 2012b. IUBMB Life 64, 455464.

Sezer, M., Santos, A., Kielb, P., Pinto, T., Martins, L.O., Todorovic, S., 2013. Biochemistry 52, 3074-3084.

Shan, D., Li, Q.-B., Ding, S.-N., Xu, J.-Q., Cosnier, S., Xue, H.-G., 2010. Biosens. Bioelectron. 26, 536-541.

Singh, R., Eltis, L.D., 2015. Arch. Biochem. Biophys. 574, 56-65.

Singh, R., Grigg, J.C., Armstrong, Z., Murphy, M.E.P., Eltis, L.D., 2012. J. Biol. Chem. 287, 10623-10630.

Smulevich, G., Feis, A., and Howes, B. D., 2005. Acc. Chem. Res. 38, 433-440.

Sugano, Y., 2009. Cell. Mol. Life Sci. 66, 1387-1403.

Todorovic, S., Hildebrandt, P., Martins, L.O., 2015. Phys. Chem. Chem. Phys. 17, 1195411957.

Todorovic, S., Jung, C., Hildebrandt, P., Murgida, D.H., 2006. J. Biol. Inorg. Chem. 11, 119127.

Todorovic, S., Rodrigues, M.L., Matos, D., Pereira, I.A.C., 2012. J. Phys. Chem. B 116, 56375643.

Todorovic, S., Verissimo, A., Wisitruangsakul, N., Zebger, I., Hildebrandt, P., Pereira, M.M., Teixeira, M., Murgida, D.H., 2008. J. Phys. Chem. B 112, 16952-16959.

van Bloois, E., Torres Pazmino, D.E., Winter, R.T., Fraaije, M.W., 2010. Appl. Microbiol. Biotechnol. 86, 1419-1430.

Villalonga, R., Díez, P., Yáñez-Sedeño, P., Pingarrón, J.M., 2011. Electrochim. Acta 56, 46724677.

Wackerbarth, H., Klar, U., Gunther, W., Hildebrandt, P., 1999. Appl. Spectrosc. 53, 283-291.

Wang, Y., Wang, Z., Rui, Y., Li, M., 2015. Biosens. Bioelectron. 64, 57-62.

Zeng, X., Li, X., Liu, X., Liu, Y., Luo, S., Kong, B., Yang, S., Wei, W., 2009. Biosens. Bioelectron. 25, 896-900.

Zhang, D., Zhao, H., Fan, Z., Li, M., Du, P., Liu, C., Li, Y., Li, H., Cao, H., 2015. PloS one 10(6), e0130156.

Zhang, R., Chen, W., 2017. Biosens. Bioelectron. 89, 249-268. 